\title{
NeuroImage
}

\section{fMRI correlates of the episodic retrieval of emotional contexts}

\author{
A.P.R. Smith, ${ }^{\mathrm{a}, \mathrm{b}, *}$ R.N.A. Henson, ${ }^{\mathrm{a}, \mathrm{b}}$ R.J. Dolan, ${ }^{\mathrm{a}}$ and M.D. Rugg ${ }^{\mathrm{b}, \mathrm{c}, 1}$ \\ ${ }^{a}$ Wellcome Department of Imaging Neuroscience, Institute of Neurology, University College London, London, UK \\ ${ }^{\mathrm{b}}$ Institute of Cognitive Neuroscience, University College London, London, UK \\ ${ }^{\mathrm{c}}$ Department of Psychology, University College London, London, UK
}

Received 30 October 2003; revised 7 January 2004; accepted 30 January 2004

\begin{abstract}
Functional neuroimaging studies reveal differences in neural correlates of the retrieval of emotional and nonemotional memories. In the present experiment, encoding of emotionally neutral pictures in association with positively, neutrally or negatively valenced background contexts led to differential modulation of neural activity elicited in a subsequent recognition memory test for these pictures. Recognition of stimuli previously studied in emotional compared to neutral contexts elicited enhanced activity in structures previously implicated in episodic memory, including the parahippocampal cortex, hippocampus and prefrontal cortex. In addition, there was engagement of structures linked more specifically to emotional processing, including the amygdala, orbitofrontal cortex and anterior cingulate cortex. These emotion-related effects displayed both valence-independent and valence-specific components. We discuss the findings in terms of current models of emotional memory retrieval.
\end{abstract}

(C) 2004 Elsevier Inc. All rights reserved.

Keywords: Emotion; Memory; Retrieval; Functional imaging

\section{Introduction}

Whereas a considerable number of neuroimaging experiments have examined interactions between emotion and memory (for review, see Hamann, 2001), only a few have examined such interactions at the time of retrieval. These latter studies have shown differences in neural activity associated with retrieval of emotional vs. neutral information. Both Taylor et al. (1998) and Dolan et al. (2000) examined differences in neural activity elicited during recognition of emotional vs. neutral pictures. Taylor et al. (1998) reported enhanced activity in visual areas, while Dolan et al. (2000) reported effects in anterior temporal lobe and amygdala during emotional retrieval. Both studies, however, utilised blocked designs, making it difficult to separate state- and item-related effects (see Otten et al., 2002). Furthermore, the reliance upon

* Corresponding author. Wellcome Department of Imaging Neuroscience, Institute of Neurology, University College London, 17 Queen Square, London WC1N 3AR, UK. Fax: +44-20-79168517.

E-mail address: adam.smith@ucl.ac.uk (A.P.R. Smith).

${ }^{1}$ Present address: Centre for the Neurobiology of Learning and Memory, University of California, Irvine, Irvine, CA 92697-3800, USA.

Available online on ScienceDirect (www.sciencedirect.com.) emotional and neutral pictures as recognition cues leads to difficulties in interpreting whether the observed effects reflected exclusively memory-related processes or included activity resulting from on-line processing of emotional information (see also Maratos and Rugg, 2001; Smith et al., in press).

A number of recent studies, using event-related designs, have investigated emotional retrieval with designs enabling contrasts of neural activity elicited by recognition of pre-experimental neutral items according to the valence of the study context (Maratos and Rugg, 2001; Maratos et al., 2001; Smith et al., in press). Maratos and Rugg (2001) reported that event-related potentials (ERPs) associated with recognition of words studied in negatively valenced sentences showed marked quantitative, and subtle qualitative, differences from ERPs elicited by recognition of words studied in neutral sentences. A subsequent fMRI study examined activity elicited during a recognition memory test for words presented at study in the context of negative, neutral or positive sentences (Maratos et al., 2001). Recognition of items encoded in negative vs. neutral sentences elicited increased neural activity in right prefrontal cortex and bilateral medial, superior and anterior temporal regions, including left hippocampus and amygdala. These findings are suggestive of enhanced memory processing and additional emotion-specific processing for these items arising from their study history. Words encoded in positive sentences showed increased activity in bilateral orbitofrontal and inferior frontal areas, left anterior and superior temporal lobes, with trends towards effects in the same regions of amygdala and hippocampus as revealed in the negative vs. neutral contrast.

In two more recent ERP experiments (Smith et al., in press), subjects formed associations between pre-experimentally neutral pictures and emotionally valenced pictorial backgrounds in a manner analogous to the verbal paradigm employed by Maratos et al. (2001). In addition to the ERP effects elicited by recognition of neutral items, which were similar to previously reported 'old/new' effects (for review, see Rugg and Allan, 2000), recognition of items encoded in emotional contexts was associated with two distinct ERP effects. Before the onset of the 'left parietal old/new effect', which has been linked to episodic retrieval (typically onsetting 400-500 ms post-stimulus; see Rugg and Allan, 2000), a small, early emotion-specific effect was evident over posterior temporal scalp locations. A later effect, onsetting after the 'left parietal' effect at around $800 \mathrm{~ms}$ 
post-stimulus, was also evident, with large positive shifts maximal over left fronto-temporal scalp. Both these emotion-related effects were temporally and topographically distinct from the 'old/new' effects elicited by items encoded in neutral contexts, indicating qualitative differences in neural activity, and presumably the cognitive processes, involved in the retrieval of emotional compared to neutral memories.

In the present experiment, event-related fMRI was employed in an experiment essentially identical to experiment 1 of Smith et al. (in press), described above. The aim was to identify neural structures and circuits supporting successful recognition of items associated at study with emotionally valenced as opposed to neutrally valenced visual contexts. Based on the ERP findings described above, and the fMRI study of Maratos et al. (2001), it was anticipated that structures involved in emotional retrieval would include those implicated in the processing of emotional stimuli and events, notably the amygdala and orbitofrontal cortices (see Bechara et al., 2000; Dolan, 2002; Zald, 2003 for reviews), together with enhanced activity in areas more generally associated with memory retrieval, such as parahippocampal cortex, hippocampus and prefrontal cortex. Crucially, the experimental design employed allowed us to determine which effects reflected qualitative differences in the retrieval of emotional and nonemotional memories, and which reflected enhanced activity in areas also engaged during retrieval of neutral memories. Furthermore, our design enabled us to assess which emotion effects were common to recognition of items encoded in negative and positive memories, and which reflected valence-specific effects. Finally, we addressed whether emotion effects elicited during retrieval overlapped with emotion-related differences observed during encoding, possibly reflecting the recapitulation or re-representation of the emotional processes elicited by initial exposure to emotional material.

\section{Materials and methods}

\section{Subjects}

Eighteen right-handed young adults (age range 18-32 years, mean 23) were employed as subjects and remunerated at $£ 7.50 / \mathrm{h}$. All were in good health with no history of neurological or psychiatric illness. Three subjects were excluded from the final analysis, one due to inadequate behavioural performance, one due to excessive movement artifact, and one due to technical problems. Of the remaining 15 subjects, 8 were female. The experiment conformed to a type approved by the joint ethics committee of the National Hospital for Neurology and Neurosurgery and the Institute of Neurology.

\section{Stimulus materials and list construction}

Stimuli consisted of two picture components, an object superimposed on a background context. Objects were presented within a yellow box to demarcate their separation from backgrounds, which were drawn principally from the International Affective Pictorial System (IAPS) (Lang et al., 1997), a series of pictures with standardised ratings for valence and arousal. About 5\% of the background materials consisted of photographs additional to the IAPS set. A subset of this combined pool of backgrounds were selected from pilot studies carried out using 12 British subjects (6 female, mean age 22 years), who assessed valence and arousal of all materials using separate 5-point Likert scales. For a few pictures, the ratings of these subjects differed significantly from the IAPS norms. These items were excluded, as were those which showed across-subject variances in rating scores greater than 0.75 .

The selected set of backgrounds consisted of 180 pictures, subdivided into three sets that were either negatively (mean 1.29, SD 0.47 ), neutrally (mean 3.06 , SD 0.43 ) or positively (mean 4.17 , SD 0.54) valenced as determined by the ratings of the pilot group. Each of the valence categories contained images of people, animals, objects and landscapes. None of the backgrounds contained sexual material. The objects that were superimposed on these backgrounds came from a wide range of semantic categories (e.g., tools, furniture, clothing, machinery). They were assessed for emotional arousal and valence by the same subjects who rated the backgrounds. Objects that deviated from neutral valence (valence mean $<2.75$ or $>3.25$; variance $>0.75$ ) or were arousing (mean arousal rating $>1.5$ ) were excluded. A total of 360 objects were employed as critical stimuli.

At study, subjects were presented with one of six study lists. Each list included the 180 selected backgrounds, arranged pseudorandomly, with no more than three pictures from the same valence category presented consecutively. Each critical object was paired with a neutral background in one list, a negative background in another, a positive background in a third, and was available as a new item for the remaining three lists. The study phase was separated into two parts to allow rest breaks, and the first two background/object pairs in each part were neutral filler items. Therefore, each study list consisted of 184 background/ object pairs (including the fillers). Each study list was paired with three test lists, consisting of 180 old items, 90 new items and 4 fillers. Each test list utilised a different set of new items, and each subject was tested on only one of the three test lists. One hundred twenty null events were randomly interspersed with the test list, allowing estimation of item-evoked responses relative to baseline. A practice study list of six background/object pairs and a practice test list of nine objects were also constructed and were used to train subjects before the experiment proper. The stimuli and lists were identical to those utilised in a previous ERP study (Smith et al., in press).

\section{Study procedure}

In the study phase, stimuli were presented via a mirror mounted on the head coil of the fMRI scanner, in direct view of the supine participant, at a distance of approximately $50 \mathrm{~cm}$ from the projection screen. The background was initially presented alone on the screen for $3 \mathrm{~s}$. During this time, subjects indicated whether they judged the backgrounds to be pleasant, unpleasant, or neutral, using a keypad in the right hand to assign them to these three categories. Three seconds after presentation of the context, the critical object was superimposed centrally upon the background, and subjects were required to imagine a connection between background and object. This connection was made covertly. The object and background were presented together for $4.5 \mathrm{~s}$, and the screen was then blanked for $750 \mathrm{~ms}$ before presentation of the next background. Six practice trials were given before the study proper, during which the subjects were required to describe verbally the connections they had made between background and object, thereby ensuring they under- 
stood the task. During the study phase proper, a rest break was given after 92 trials, the first two trials of each of the subphases being neutral filler items.

\section{Test procedure}

The test phase followed the study phase after a delay of around 5 min, during which a serial subtraction task was performed to prevent rehearsal. Stimulus delivery used the same setup as during study. A white asterisk was presented against a black background for $500 \mathrm{~ms}$, following which the test item was presented for a duration of $750 \mathrm{~ms}$. This was followed by a white fixation cross on a black background for approximately $2 \mathrm{~s}$ before presentation of the asterisk denoted the imminent onset of a new trial. This sequence of events gave a stimulus onset asynchrony (SOA) of $3.25 \mathrm{~s}$. One hundred twenty 'null events', consisting of the white fixation cross for an additional $1.25 \mathrm{~s}$ in place of the white asterisk and test item, were incorporated into the test list, allowing estimation of baseline. Subjects were instructed to respond, as quickly and accurately as possible, with one button of the keypad when the object depicted had been presented in the preceding study phase, and with another button if it was being viewed for the first time. Assignment of finger responses was counterbalanced across subjects. The test list was split into two equal parts, with the first two stimuli of each subphase being filler items. Before the test phase proper, an example test phase was given, containing the six items from the practice study list, plus three new items. None of these items appeared in the subsequent test list.

\section{Imaging and image processing}

MRI data were acquired from a 1.5-T Siemens SONATA system (Siemens, Erlangen, Germany) equipped with a head coil. Functional images were acquired with a gradient echo-planar T2* sequence using BOLD (blood oxygenation level dependent) contrast, with a repetition time $(\mathrm{TR})=2.7 \mathrm{~s}$, giving an effective sampling rate of approximately $2 \mathrm{~Hz}$ at both study and test. Thirty slices of $2.5-\mathrm{mm}$ thickness were acquired, with an interslice gap of $1.3 \mathrm{~mm}$, giving whole brain coverage, with the exception of the vertex. Data were acquired during four separate sessions (two each at study and test) with the first five volumes of each session discarded to allow for $\mathrm{T} 1$ equilibration effects. Images were realigned, slice-time corrected, normalised to a standard echoplanar image template and smoothed with a Gaussian kernel with full-width half maximum of $8 \mathrm{~mm}$.

\section{Statistical analysis of images}

Data were analysed using Statistical Parametric Mapping (SPM2; Wellcome Department of Imaging Neuroscience, London, UK; Friston et al., 1995) using a random-effects analysis. Test data were modelled as eight discrete event types: old items from each of the three categories of old items (neutral, negative, positive) were separated according to whether they were correctly judged as old (hits) or incorrectly judged to be new (misses), new items were separated into those that were correctly rejected as new (correct rejections), or incorrectly judged to be old (false alarms). Also modelled separately were the two filler items at the start of each list, and those trials where no response was logged. Principal contrasts were between those events that received correct responses (i.e., hits and correct rejections).
Study data were modelled as $9 \mathrm{~s}$ epochs of seven types. Each class of encoding event was divided into those items that were recognised in the subsequent test phase and those that were not, with a final event type consisting of the filler trials at the start of each study list and events where responses were not logged. Analyses were restricted to those items that were subsequently correctly recognised, so as to ensure that contrasts revealed emotion effects, rather than 'subsequent memory effects', which could arise if different proportions of forgotten and remembered items were obtained in the different valence categories.

Regressor modelling events and epochs were convolved with a standard canonical haemodynamic response function, along with its temporal and dispersion derivatives (Friston et al., 1998). For the analyses of both study and test data, movement parameters were modelled as potentially confounding covariates. For both study and test, assignment of stimuli to valence categories was based on the judgments of each individual subject. Linear contrasts of parameter estimates were estimated for each subject, and initial statistical parametric maps (SPMs) were generated by an ANOVA incorporating the canonical HRF and its derivatives (see above) for each condition [corrected for nonsphericity using a restricted maximum likelihood (ReML) procedure; Friston et al., 2002]. All significant effects obtained with this contrast were found to be carried by the canonical HRF, so subsequent analyses were based on SPMs of the $t$ statistic derived from contrasts utilizing this basis function alone. For some contrasts, positive and negative hits were collapsed to form a single 'emotional hit' condition, analogous to our previous ERP studies (Smith et al., in press).

\section{Results}

\section{Behavioural results}

Recognition accuracies, and associated reaction times (RTs), are shown in Table 1. ANOVA conducted on hit rates showed a main effect of condition $[F(1.4,20)=7.65 ; P<0.01]$. Subsidiary ANOVAs revealed that items encoded in positively valenced contexts were more likely to be recognised than items encoded in neutrally $[F(1,14)=38.6 ; P<0.001]$ or negatively $[F(1,14)=$ 5.87; $P<0.05]$ valenced contexts. There was no significant difference in the recognition rates for items encoded in negatively vs. neutrally valenced contexts $(F<1)$. There were no significant differences in RTs to hits.

\section{fMRI data}

The principal contrasts of interest were (i) common effects for the three hit conditions (neutral, negative and positive) vs. correct rejections (old/new effects), (ii) between a collapsed emotional hit condition (weighted combination of positive and negative hits) and neutral hits (valence-independent emotion effects) and (iii) between positive and negative hits (valence-specific effects). The mean number of trials (range in parentheses) contributing to each

Table 1

Mean accuracies and reaction times (standard deviations in parentheses)

\begin{tabular}{lcccc}
\hline & Neutral & Negative & Positive & \multicolumn{1}{l}{ New } \\
\hline Accuracy & $0.79(0.09)$ & $0.80(0.09)$ & $0.84(0.08)$ & $0.90(0.07)$ \\
RT (ms) & $958(224)$ & $948(212)$ & $945(250)$ & $1036(260)$ \\
\hline
\end{tabular}


Table 2

Common old/new effects (inclusive mask of neutral, negative and positive hits-correct rejections; $P<0.001$, uncorrected)

\begin{tabular}{|c|c|c|c|c|c|c|c|}
\hline \multicolumn{3}{|c|}{ Region } & \multirow{3}{*}{$\begin{array}{c}\text { Voxels } \\
41\end{array}$} & \multicolumn{3}{|c|}{ Peak coordinates } & \multirow{3}{*}{$\begin{array}{l}\text { Peak } Z \\
4.29\end{array}$} \\
\hline & & & & \multirow{2}{*}{$\frac{x}{-6}$} & \multirow{2}{*}{$\frac{y}{-68}$} & \multirow{2}{*}{$\frac{z}{18}$} & \\
\hline $\mathrm{L}$ & Precuneus & (BA 31) & & & & & \\
\hline $\mathrm{L}$ & Angular gyrus & (BA 39) & 40 & -46 & -68 & 32 & 3.64 \\
\hline $\mathrm{L}$ & $\begin{array}{l}\text { Superior } \\
\text { parietal lobule }\end{array}$ & (BA 7) & 49 & -34 & -64 & 50 & 4.29 \\
\hline $\mathrm{L}$ & $\begin{array}{l}\text { Superior } \\
\text { parietal lobule }\end{array}$ & (BA 7) & 22 & -26 & -60 & 46 & 3.59 \\
\hline $\mathrm{L}$ & $\begin{array}{l}\text { Inferior } \\
\text { parietal lobule }\end{array}$ & (BA 40) & 109 & -44 & -58 & 40 & 4.91 \\
\hline $\mathrm{L}$ & $\begin{array}{l}\text { Posterior } \\
\text { cingulate }\end{array}$ & (BA 31) & 68 & -4 & -56 & 26 & 3.37 \\
\hline $\mathrm{L}$ & Cingulate gyrus & (BA 31) & 5 & -10 & -44 & 30 & 3.39 \\
\hline $\mathrm{L}$ & $\begin{array}{l}\text { Middle temporal } \\
\text { gyrus }\end{array}$ & (BA 21) & 29 & -64 & -42 & -8 & 3.46 \\
\hline $\mathrm{L}$ & $\begin{array}{l}\text { Inferior frontal } \\
\text { gyrus }\end{array}$ & (BA 46) & 6 & -42 & 32 & 10 & 3.49 \\
\hline $\mathrm{L}$ & $\begin{array}{l}\text { Middle frontal } \\
\text { gyrus }\end{array}$ & (BA 10) & 47 & -32 & 50 & 0 & 3.97 \\
\hline
\end{tabular}

All Brodmann areas are approximations based on peak coordinates.

of the critical conditions were neutral hits, 44 (33-55); negative hits, 45 (30-59); positive hits, $46(30-58)$; correct rejections, 75 $(50-87)$. The reported contrasts were all based on one-tailed $t$ tests with a significance level of $P<0.001$, and a spatial extent threshold of at least five contiguous voxels. In a number of cases, contrasts were used as 'masks' for one another. 'Inclusive' masking reveals voxels common to two or more contrasts, allowing characterisation of brain areas sensitive to a common feature of different contrasts (such as old vs. new for different item categories), as well as areas sensitive to multiple experimental factors (such as memory and emotion). 'Exclusive' masks reveal voxels in one contrast that do not overlap with those from one or more different contrasts, implying specificity of the effects elicited.

Unless stated otherwise, 'inclusive' masks employed contrasts thresholded at $P<0.001$, while 'exclusive' masks were thresholded at $P<0.05$ (the lower significance level here increases the confidence with which it can be concluded that two contrasts did not overlap).

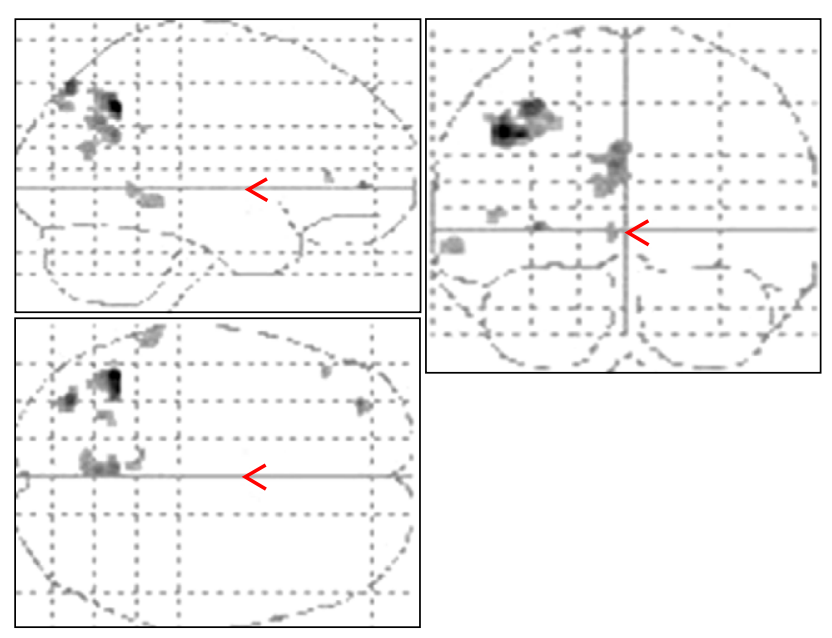

Fig. 1. Old/new effects common to neutral, negative and positive hits (thresholded at $P<0.001$, uncorrected).
Table 3a

Regions showing significant signal increases for emotional vs. neutral hits $(P<0.001$, uncorrected; exclusively masked with negative-positive and positive-negative hits at $P<0.05$, uncorrected)

\begin{tabular}{|c|c|c|c|c|c|c|c|}
\hline \multicolumn{3}{|c|}{ Region } & \multirow{3}{*}{$\begin{array}{l}\text { Voxels } \\
26\end{array}$} & \multicolumn{3}{|c|}{ Peak coordinates } & \multirow{3}{*}{$\begin{array}{c}\text { Peak } Z \\
5.43\end{array}$} \\
\hline & & & & \multirow{2}{*}{$\frac{x}{-20}$} & \multirow{2}{*}{$\begin{array}{l}y \\
-74\end{array}$} & \multirow{2}{*}{$\frac{z}{-8}$} & \\
\hline $\mathrm{L}$ & Lingual gyrus & (BA 18) & & & & & \\
\hline $\mathrm{L}$ & Angular gyrus & (BA 39) & 35 & -44 & -68 & 34 & 3.68 \\
\hline $\mathrm{L}$ & $\begin{array}{l}\text { Middle temporal } \\
\text { gyrus }\end{array}$ & (BA 21) & 23 & -64 & -44 & -2 & 3.8 \\
\hline $\mathrm{R}$ & Parietal lobe & & 5 & 30 & -40 & 30 & 3.66 \\
\hline $\mathrm{L}$ & Insula & & 5 & -48 & -26 & 16 & 3.25 \\
\hline $\mathrm{L}$ & Precentral gyrus & & 13 & -48 & -6 & 24 & 3.9 \\
\hline $\mathrm{L}$ & Amygdala & & 57 & -26 & -4 & -16 & 4.66 \\
\hline $\mathrm{R}$ & $\begin{array}{l}\text { Anterior } \\
\text { cingulate }\end{array}$ & (BA 32) & 12 & 12 & 44 & 6 & 3.3 \\
\hline $\mathrm{R}$ & $\begin{array}{l}\text { Inferior frontal } \\
\text { gyrus }\end{array}$ & (BA 46) & 8 & 56 & 28 & 10 & 3.35 \\
\hline $\mathrm{L}$ & $\begin{array}{l}\text { Medial } \\
\text { orbitofrontal }\end{array}$ & (BA 11) & 5 & -2 & 46 & -20 & 3.4 \\
\hline $\mathrm{L}$ & $\begin{array}{l}\text { Medial frontal } \\
\text { gyrus }\end{array}$ & (BA 10) & 16 & -10 & 62 & 10 & 4.02 \\
\hline
\end{tabular}

\section{Common old/new effects}

An inclusive mask incorporating old/new effects (i.e., hitcorrect rejection contrasts) from neutral, negative and positive hits revealed memory effects common to retrieval of emotional and neutral memories (Table 2). Significant effects were elicited in left lateral parietal and posterior cingulate cortex, precuneus, angular gyrus, middle temporal gyrus and left prefrontal cortex (Fig. 1). These areas correspond closely to those reported in other eventrelated fMRI studies of recognition memory (e.g., Henson et al., 1999a; Konishi et al., 2000; Maratos et al., 2001; see Rugg et al., 2002 for review). To examine if any of these effects were enhanced during retrieval of emotional memories, the old/new contrast was inclusively masked with the contrast used to identify valenceindependent emotion effects (see below). Effects in the left angular gyrus and left middle temporal gyrus survived this masking, and therefore presumably reflect memory effects that are enhanced when retrieved memories are emotional.

\section{Valence-independent emotion effects}

To identify valence-independent emotion effects, the contrast between emotional and neutral hits was exclusively masked by the two contrasts used to identify valence-specific effects (see below). The results of this contrast are listed in Table $3 \mathrm{a}$.

Table 3b

Regions showing significant signal increases for neutral vs. emotional hits $(P<0.001$, uncorrected $)$

\begin{tabular}{|c|c|c|c|c|c|c|c|}
\hline \multicolumn{3}{|c|}{ Region } & \multirow{3}{*}{$\begin{array}{l}\text { Voxels } \\
25\end{array}$} & \multicolumn{3}{|c|}{ Peak coordinates } & \multirow{3}{*}{$\begin{array}{l}\text { Peak } Z \\
3.8\end{array}$} \\
\hline & & & & \multirow{2}{*}{$\frac{x}{-28}$} & \multirow{2}{*}{$\begin{array}{l}y \\
-84\end{array}$} & \multirow{2}{*}{$\frac{z}{0}$} & \\
\hline $\mathrm{L}$ & $\begin{array}{l}\text { Middle } \\
\text { occipital gyrus }\end{array}$ & (BA 18) & & & & & \\
\hline $\mathrm{L}$ & $\begin{array}{l}\text { Posterior } \\
\text { cingulate }\end{array}$ & & 7 & -14 & -52 & 16 & 3.68 \\
\hline $\mathrm{L}$ & Cerebellum & & 16 & -6 & -50 & -34 & 3.97 \\
\hline $\mathrm{R}$ & $\begin{array}{l}\text { Middle } \\
\text { temporal gyrus }\end{array}$ & (BA 21) & 9 & 40 & -6 & -28 & 3.41 \\
\hline
\end{tabular}




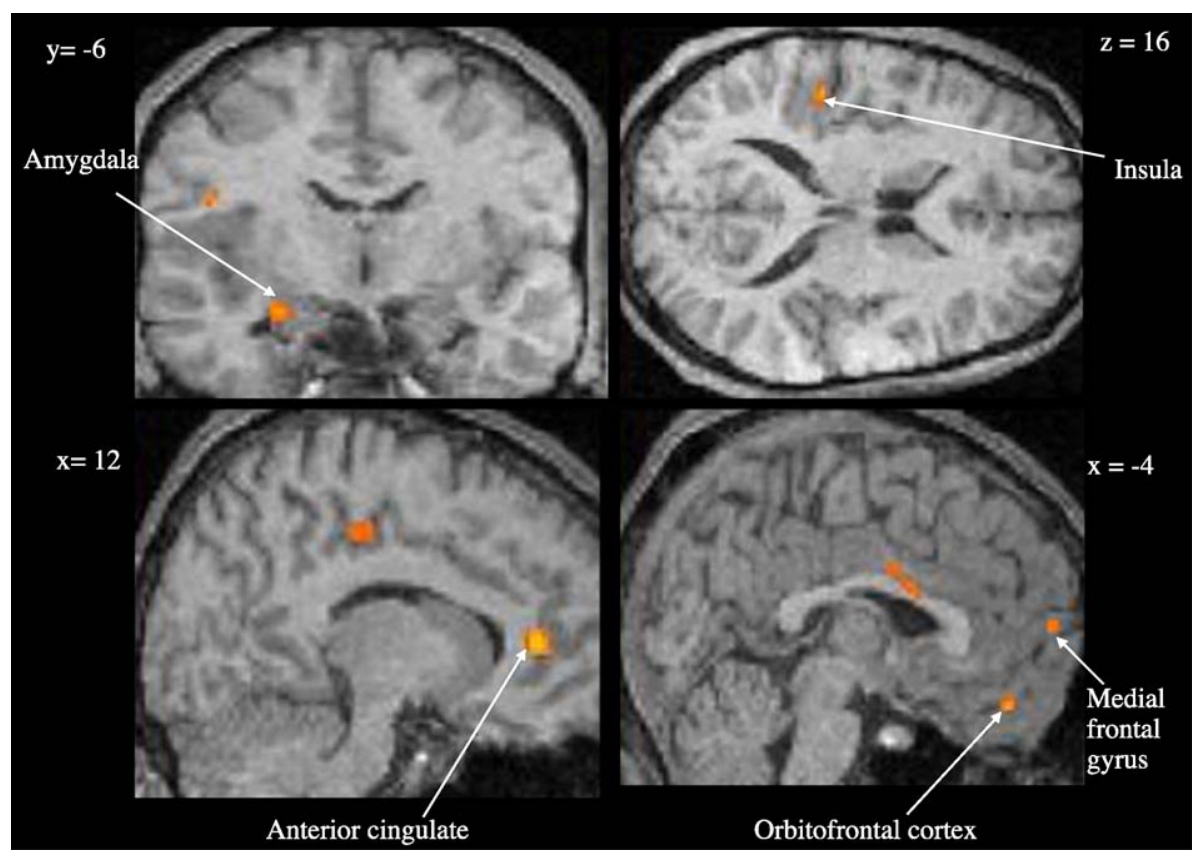

Fig. 2. Selected regions identified in the contrast between hits from emotional vs. neutral conditions (thresholded at $P<0.005$, uncorrected) displayed on normalised EPI images from a single subject.

A number of these effects survived exclusive masking with the neutral old/new contrast, suggesting that they might be emotionspecific. These included effects in left amygdala, left lingual gyrus, left insula, right mid- and anterior cingulate, right inferior frontal gyrus, left medial orbitofrontal cortex and medial frontal gyrus (Figs. 2-6). Regions of the left middle occipital gyrus, left cerebellum, left posterior cingulate and right middle temporal gyrus showed significantly greater haemodynamic responses during recognition of items encoded in neutral vs. emotional contexts (Table 3b).

\section{Valence-specific emotion effects}

Negative hits elicited greater activity than positive hits in several regions (Table 4) including left fusiform, left middle

Table 4

Regions showing significant signal increases for negative vs. positive hits $(P<0.001$, uncorrected $)$

\begin{tabular}{|c|c|c|c|c|c|c|c|}
\hline \multicolumn{3}{|c|}{ Region } & \multirow{3}{*}{$\begin{array}{l}\text { Voxels } \\
5\end{array}$} & \multicolumn{3}{|c|}{ Peak coordinates } & \multirow{3}{*}{$\begin{array}{l}\text { Peak } Z \\
3.48\end{array}$} \\
\hline & & & & \multirow{2}{*}{$\frac{x}{20}$} & \multirow{2}{*}{$\frac{y}{-90}$} & \multirow{2}{*}{$\frac{z}{8}$} & \\
\hline $\mathrm{R}$ & Cuneus & & & & & & \\
\hline $\mathrm{L}$ & Cuneus & & 10 & -6 & -88 & 12 & 3.34 \\
\hline $\mathrm{L}$ & $\begin{array}{l}\text { Middle } \\
\text { occipital gyrus }\end{array}$ & (BA 37) & 31 & -50 & -66 & -8 & 3.26 \\
\hline $\mathrm{L}$ & Fusiform gyrus & (BA 37) & 5 & -48 & -58 & -12 & 3.33 \\
\hline $\mathrm{L}$ & $\begin{array}{l}\text { Middle } \\
\text { temporal gyrus }\end{array}$ & (BA 21) & 8 & -64 & -42 & -4 & 3.2 \\
\hline $\mathrm{R}$ & $\begin{array}{l}\text { Middle } \\
\text { temporal gyrus }\end{array}$ & (BA 38) & 5 & 38 & 6 & -36 & 3.4 \\
\hline $\mathrm{L}$ & $\begin{array}{l}\text { Medial } \\
\text { frontal gyrus }\end{array}$ & (BA 6) & 14 & -14 & 10 & 50 & 3.46 \\
\hline $\mathrm{L}$ & $\begin{array}{l}\text { Medial } \\
\text { frontal gyrus }\end{array}$ & (BA 9) & 5 & -8 & 28 & 30 & 3.12 \\
\hline
\end{tabular}

occipital gyrus, bilateral middle temporal gyri, bilateral cuneus and left medial frontal gyrus. Regions in the right precuneus and left inferior parietal lobule were significantly more active for positive vs. negative hits (Table 5). Additionally, a contrast of positive hits and correct rejections revealed effects in the left parahippocampal region, right hippocampus and left medial frontal gyrus, while a contrast between negative and neutral hits revealed effects in right parahippocampal gyrus and right anterior temporal lobe.

\section{Common emotional effects at encoding and retrieval}

A number of regions identified in the retrieval contrasts also showed effects in a contrast that revealed emotion-related differences in activity during the encoding of those items that were subsequently recognised. Valence-independent effects of emotion at encoding are reported in Table 6 and included visual extrastriate areas, amygdala and prefrontal cortex (Fig. 7), regions previously reported to be activated during the viewing or rating of emotional pictures (Lane et al., 1999; Phan et al., 2003). Inclusive masking revealed that overlapping regions of left angular gyrus and left amygdala were more active during both the encoding of the emotional material and subsequent recognition of the associated items.

Table 5

Regions showing significant signal increases for positive vs. negative hits $(P<0.001$, uncorrected $)$

\begin{tabular}{|c|c|c|c|c|c|c|c|}
\hline \multicolumn{3}{|c|}{ Region } & \multirow[t]{2}{*}{ Voxels } & \multicolumn{3}{|c|}{ Peak coordinates } & \multirow[t]{2}{*}{ Peak $Z$} \\
\hline & & & & $x$ & $y$ & $z$ & \\
\hline $\mathrm{R}$ & Precuneus & (BA 7) & 6 & 16 & -68 & 50 & 3.27 \\
\hline $\mathrm{L}$ & $\begin{array}{l}\text { Inferior } \\
\text { parietal lobule }\end{array}$ & (BA 40) & 5 & -40 & -30 & 30 & 3.48 \\
\hline
\end{tabular}




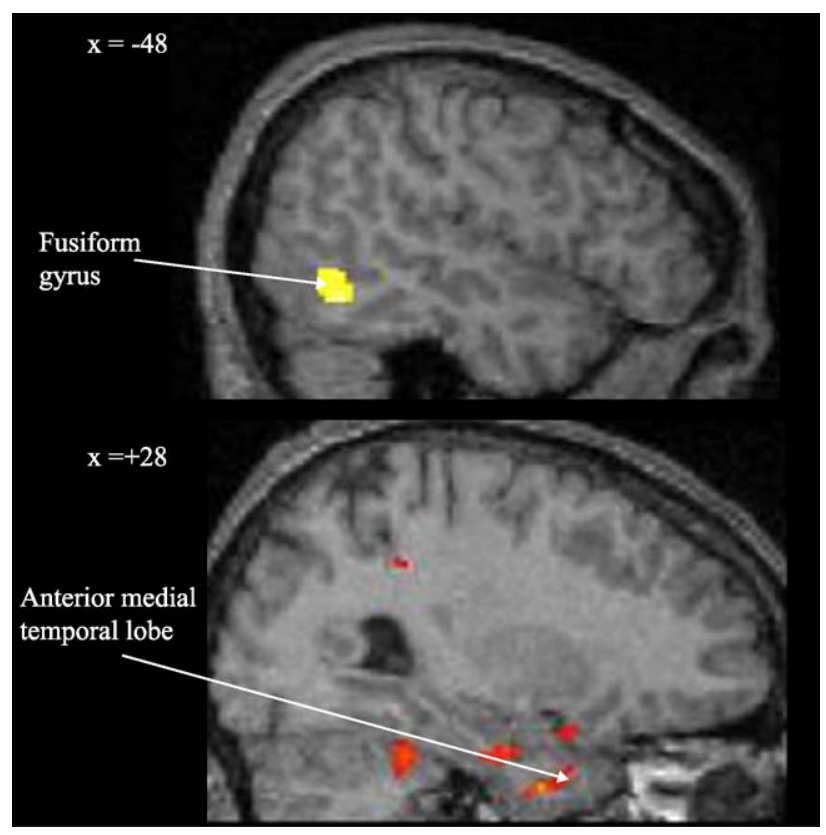

Fig. 3. Regions identified in the contrast of negative vs. neutral hits not revealed in the valence-independent contrast (thresholded at $P<0.005$, uncorrected).

Overlapping areas of left fusiform gyrus showed effects during both encoding and recognition of items associated with negative backgrounds compared to items associated with either positive or neutral backgrounds (Table 7).

\section{Discussion}

\section{Behavioural performance}

Items encoded in positively valenced contexts were more likely to be correctly recognised than those encoded in either neutral or negative contexts. This result is consistent with a previous study utilising the same paradigm (Smith et al., in press) and with another recent study, which investigated subsequent memory effects for emotional context and pre-experimentally neutral stimuli (Erk et al., 2003). One possibility is that the emotional backgrounds acted to enhance attention during encoding, which may have facilitated the encoding of the associated neutral items. However, where these backgrounds were extreme and especially attention-grabbing, as for some of the negative backgrounds, attention may have been diverted away from the critical neutral stimuli, thereby impairing encoding. By this argument, moderately arousing backgrounds enhance encoding of associated items, whereas strongly arousing backgrounds might impair it. Such a hypothesis has resonance with a recent study that reported that encoding of arousing, negatively valenced stimuli was associated with amnesia for other items encoded in close temporal proximity to the emotional item (Strange et al., 2003), while we have previously observed a trend using the present paradigm for the most highly arousing negative contexts to be associated with poorer recognition performance than more moderately arousing contexts (unpublished data). This may be interesting to examine further in future, using a wider range of arousal ratings to improve resolution, and objective measures of arousal, such as skin conductance.

A further explanation for the differences in performance for positive and negative conditions is that modulatory neurotransmitters mediating emotion effects on memory may be valence-specific. Thus, the modulatory effects of positive emotion may be principally mediated through increased dopamine release (see Ashby et al., 1999), with negative emotion being principally adrenergic (see Cahill, 1999). Within this framework, enhanced adrenergic drive may direct resources towards processing of an arousing stimulus, dopamine facilitates processing of other environmental elements, or binding of such elements with a positively valenced stimulus.

\section{fMRI data}

The principal aim of this study was to investigate differences between the neural correlates of recognition of items encoded in emotional compared to nonemotional backgrounds. Differences in retrieval-related neural activity are attributable to two potential mechanisms. Firstly, the emotional significance or valence of the neutral stimuli themselves may be modified by association with emotional backgrounds, giving rise to emotion effects that are independent of any episodic retrieval of associated contextual information. Secondly, the neutral stimuli may act as retrieval cues for the study contexts, with the retrieved information eliciting differential neural activity. We have previously reported ERP evidence for each of these types of emotion effect (Smith et al., in press). In the future, it would be of interest to determine if there are behavioural correlates of the proposed 'item' effects, e.g., comparing preference judgements before and after encoding for those items that had been paired with emotional backgrounds, but where this pairing was not remembered by subjects (such that judgements truly reflect a change in the value of the item, independent of any source effects at retrieval).

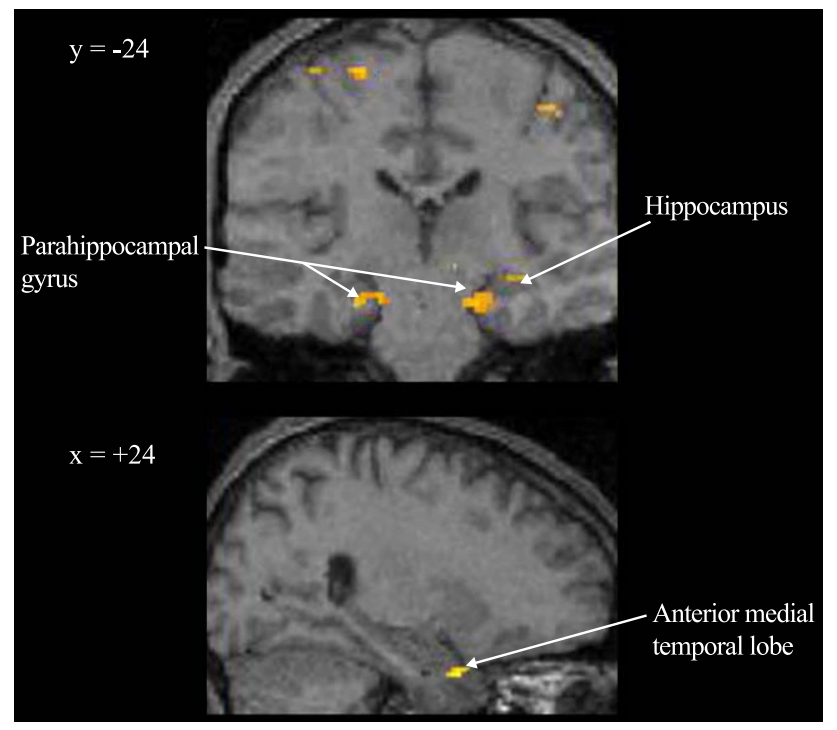

Fig. 4. Regions identified in the contrast of positive vs. neutral hits not revealed in the valence-independent contrast (thresholded at $P<0.005$, uncorrected). 


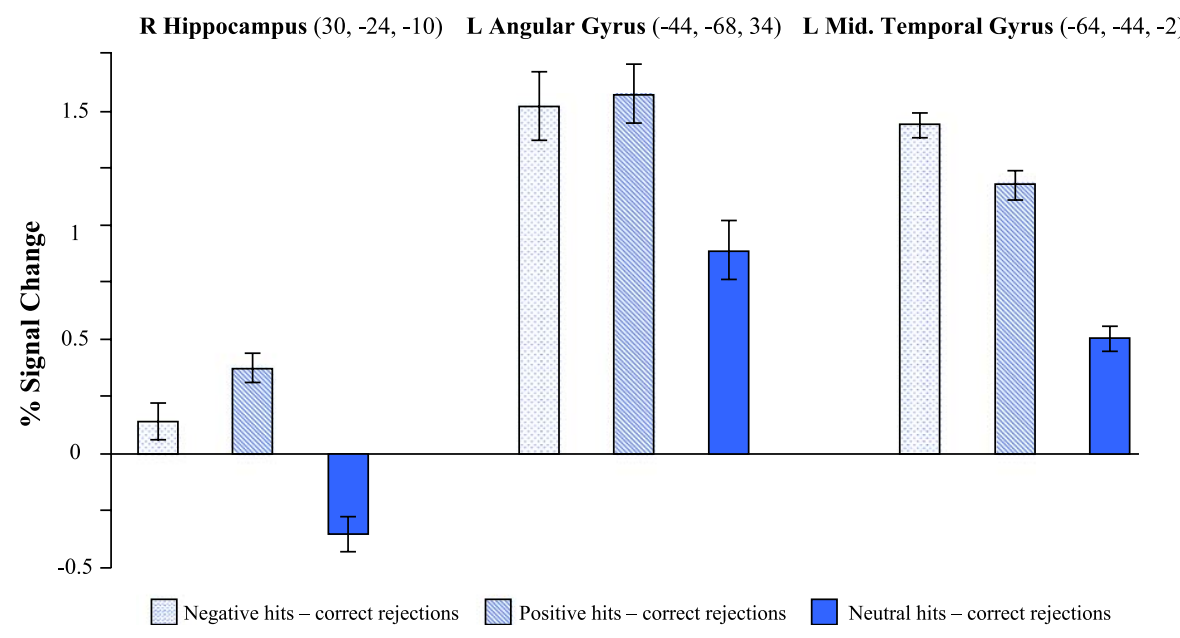

Fig. 5. Percentage signal change and associated standard errors for negative, positive and neutral hits vs. correct rejections at the regions indicated, reflecting potentiated memory processing.

\section{Modulation of episodic memory}

The contrast of hits and correct rejections revealed effects in areas previously reported in event-related studies of recognition memory, including left parietal cortex, posterior cingulate and left prefrontal cortex (see Rugg et al., 2002 for review), as well as in other areas including the angular gyrus and middle temporal gyrus. The angular gyrus (BA 39) and middle temporal gyrus (BA 21) showed old/new effects for all items, but these were significantly greater for emotional than neutral hits. Thus, one effect of the emotional manipulation was to increase activity in regions that support episodic retrieval. In particular, the angular gyrus has been identified as being an important component of the semantic memory system (see Price, 2000), and effects here may reflect increased semantic processing of items previously associated with emotional contexts because they are 'tagged' as being significant in some sense.

Emotion effects were also elicited in other structures implicated in episodic memory retrieval, including the hippocampus, para- hippocampal areas and dorsolateral prefrontal cortex (DLPFC) (see also Maratos et al., 2001). Compared to correct rejections, neutral hits showed a decrease in BOLD signal in the hippocampus (see Fig. 5), similar to some previous findings in the hippocampus itself (Rombouts et al., 2001) and nearby areas of anterior MTL (Henson et al., 2003). In contrast, emotional hits showed greater BOLD signal than correct rejections. Two distinct possibilities may explain these differences between emotional and neutral hits. Firstly, this effect may reflect that recognition of items encoded in emotional vs. neutral contexts is associated with retrieval of a greater amount of episodic information, which has been reported to correlate with hippocampal activity (Cansino et al., 2002; Eldridge et al., 2000). Secondly, hippocampal effects may relate to incidental encoding activity during the recognition test (see Stark and Okado, 2003): Encoding activity is generally highest for novel stimuli, but items previously associated with emotional backgrounds may be 'tagged' as significant, resulting in increased resources being dedicated to their (re)encoding at the time of test. Such enhanced encoding might result from an amygdala-mediated

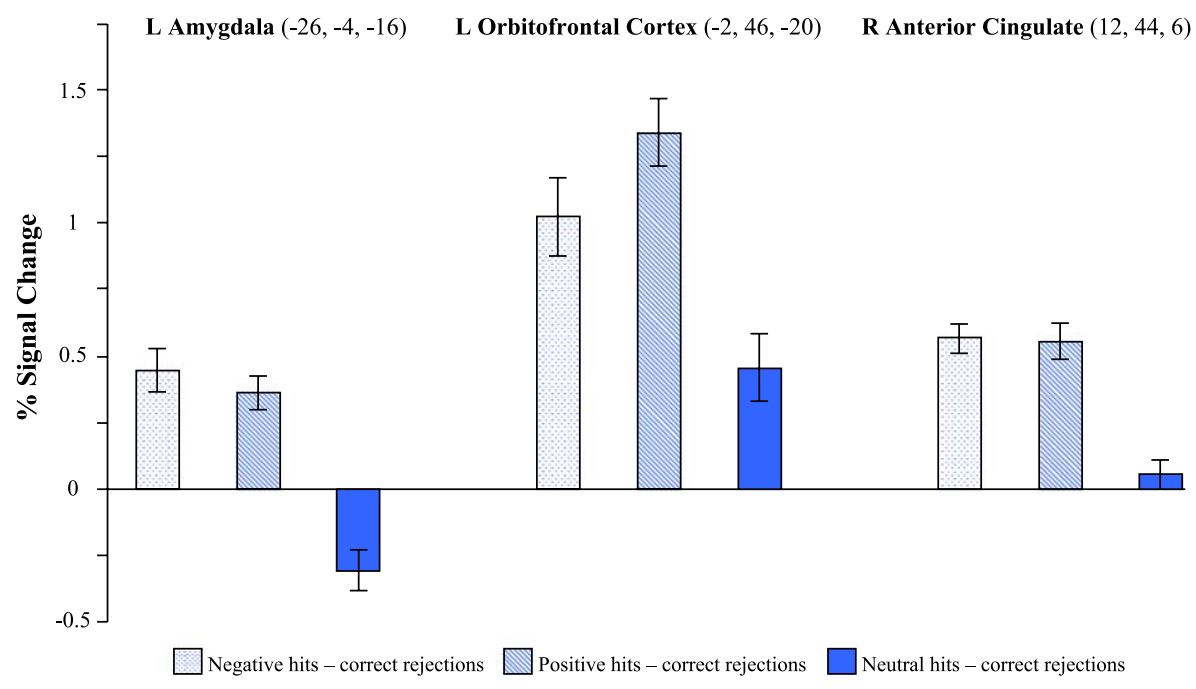

Fig. 6. Percentage signal change and associated standard errors for negative, positive and neutral hits vs. correct rejections at the regions indicated reflecting engagement of areas associated with emotional processing. 


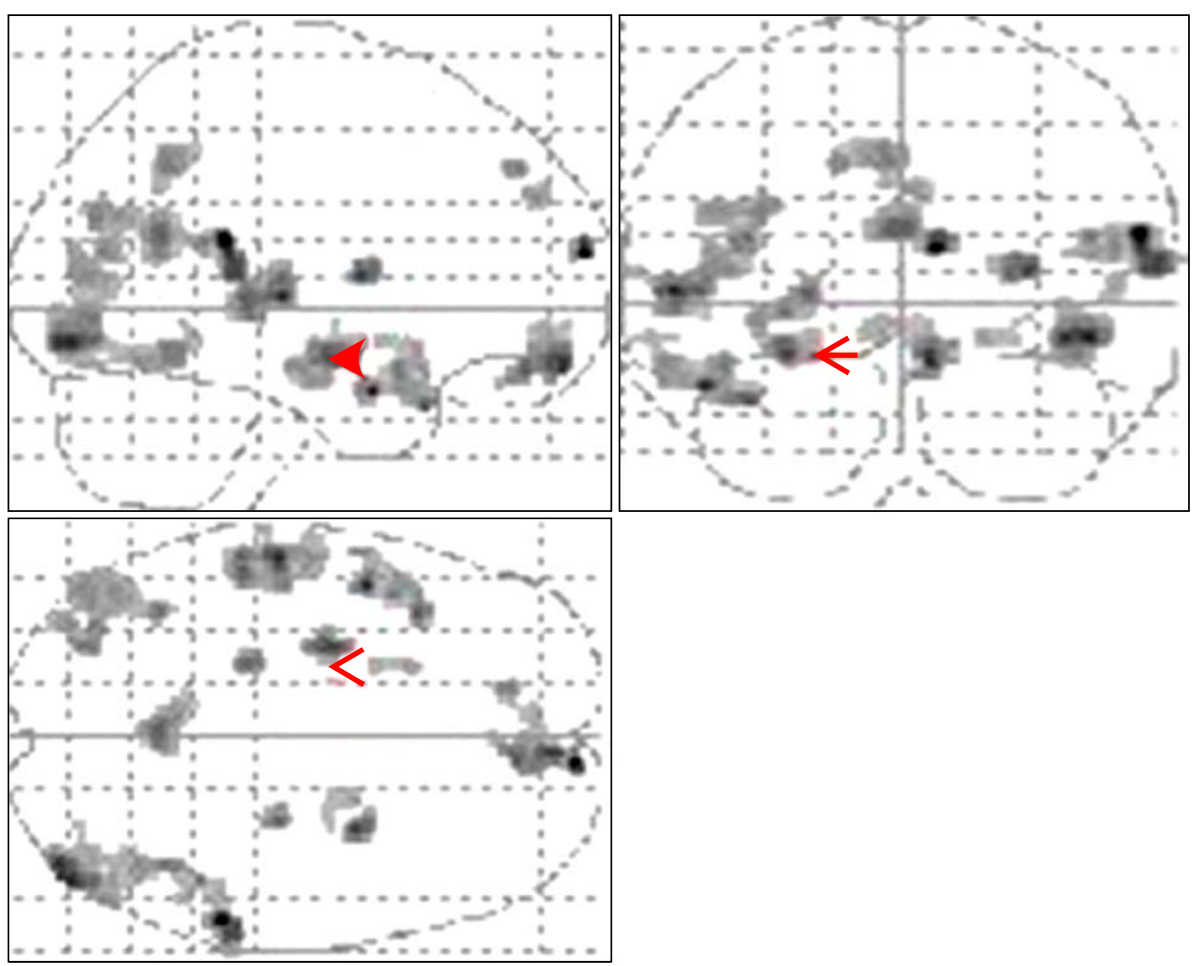

Fig. 7. Regions identified by the contrast of encoding subsequently remembered items in emotional vs. neutral contexts (thresholded at $P<0.001$, uncorrected).

modulation of hippocampal activity (see McGaugh et al., 1996), both at the time of initial encoding and at the time of retrieval/reencoding. A similar re-encoding process might explain the enhanced activity in parahippocampal areas, which have previously been reported to show novelty/familiarity responses (Henson et al., 2003), and have also been associated with subsequent memory performance for emotional stimuli in a contextual paradigm (Erk et al., 2003).

Table 6

Regions showing significant signal increases for negative vs. neutral hits (A) and positive vs. neutral hits (B) not revealed in the valence independent contrast (see Table 3) (both $P<0.001$, uncorrected)

\begin{tabular}{|c|c|c|c|c|c|c|c|}
\hline \multicolumn{3}{|c|}{ Region } & \multirow[t]{2}{*}{ Voxels } & \multicolumn{3}{|c|}{ Peak coordinates } & \multirow[t]{2}{*}{$\overline{\text { Peak } Z}$} \\
\hline & & & & $x$ & $y$ & $z$ & \\
\hline \multicolumn{8}{|c|}{ (A) } \\
\hline $\mathrm{L}$ & $\begin{array}{l}\text { Parahippocampal } \\
\text { gyrus }\end{array}$ & (BA 35) & 61 & -22 & -28 & -18 & 4.09 \\
\hline $\mathrm{R}$ & Hippocampus & & 6 & 30 & -24 & -10 & 3.26 \\
\hline $\mathrm{R}$ & $\begin{array}{l}\text { Anterior } \\
\text { temporal lobe }\end{array}$ & (BA 28) & 12 & 24 & 6 & -30 & 4.19 \\
\hline $\mathrm{R}$ & $\begin{array}{l}\text { Middle frontal } \\
\text { gyrus }\end{array}$ & (BA 9) & 7 & 34 & 38 & 36 & 3.35 \\
\hline $\mathrm{L}$ & $\begin{array}{l}\text { Medial frontal } \\
\text { gyrus }\end{array}$ & (BA 10) & 64 & -8 & 60 & 2 & 4.67 \\
\hline \multicolumn{8}{|c|}{ (B) } \\
\hline $\mathrm{R}$ & $\begin{array}{l}\text { Parahippocampal } \\
\text { gyrus }\end{array}$ & (BA 35) & 8 & 24 & -24 & -18 & 3.35 \\
\hline $\mathrm{R}$ & $\begin{array}{l}\text { Anterior temporal } \\
\text { lobe }\end{array}$ & (BA 34) & 160 & 14 & -10 & -16 & 4.59 \\
\hline
\end{tabular}

Right DLPFC has been linked to post-retrieval monitoring of retrieved information (Henson et al., 1999a,b, 2000). Recognition of items encoded in emotional vs. neutral contexts may be associated with a higher probability of incidental retrieval of episodic information, or with a quantitatively greater amount of information being retrieved, in either case increasing the amount of information to be monitored; alternatively, the same amount of information may be more closely monitored when it has emotional

Table 7

Regions showing significant signal increases for encoding of objects in emotional vs. neutral contexts $(P<0.001$, uncorrected $)$

\begin{tabular}{|c|c|c|c|c|c|c|c|}
\hline \multicolumn{3}{|c|}{ Region } & \multirow{3}{*}{$\begin{array}{l}\text { Voxels } \\
317\end{array}$} & \multicolumn{3}{|c|}{ Peak coordinates } & \multirow{3}{*}{$\begin{array}{l}\text { Peak } Z \\
4.99\end{array}$} \\
\hline & & & & \multirow{2}{*}{$\begin{array}{r}x \\
46\end{array}$} & \multirow{2}{*}{$\frac{y}{-82}$} & \multirow{2}{*}{$\frac{z}{-10}$} & \\
\hline $\mathrm{R}$ & $\begin{array}{l}\text { Inferior occipital } \\
\text { gyrus }\end{array}$ & (BA 18) & & & & & \\
\hline $\mathrm{L}$ & Angular gyrus & (BA 39) & 64 & -40 & -70 & 30 & 4.21 \\
\hline $\mathrm{L}$ & Posterior cingulate & (BA 31) & 130 & -2 & -56 & 22 & 4.46 \\
\hline $\mathrm{R}$ & $\begin{array}{l}\text { Superior temporal } \\
\text { gyrus }\end{array}$ & (BA 13) & 144 & 58 & -38 & 20 & 5.54 \\
\hline $\mathrm{L}$ & $\begin{array}{l}\text { Superior temporal } \\
\text { gyrus }\end{array}$ & (BA 22) & 169 & -56 & -26 & 4 & 4.96 \\
\hline $\mathrm{L}$ & Thalamus & & 53 & -24 & -30 & 2 & 4.37 \\
\hline $\mathrm{R}$ & Thalamus & & 36 & 26 & -22 & 8 & 4.33 \\
\hline $\mathrm{L}$ & Amygdala & & 109 & -28 & -6 & -14 & 4.69 \\
\hline $\mathrm{R}$ & Putamen & & 46 & 30 & 2 & 10 & 4.74 \\
\hline $\mathrm{L}$ & $\begin{array}{l}\text { Middle temporal } \\
\text { gyrus }\end{array}$ & (BA 21) & 159 & -48 & 8 & -24 & 4.96 \\
\hline $\mathrm{R}$ & $\begin{array}{l}\text { Medial frontal } \\
\text { gyrus }\end{array}$ & (BA 11) & 117 & 6 & 58 & -16 & 4.85 \\
\hline $\mathrm{R}$ & $\begin{array}{l}\text { Superior frontal } \\
\text { gyrus }\end{array}$ & (BA 10) & 25 & 8 & 64 & 16 & 5.34 \\
\hline
\end{tabular}


significance (at least when the information is not task relevant; see also Maratos et al., 2001). Differences have previously been reported in the 'right frontal old/new effect' in an ERP recognition study of words encoded in negative vs. neutral sentences (Maratos and Rugg, 2001) consistent with the present proposal.

\section{Emotion-specific effects}

A number of effects survived exclusive masking with the neutral hits - correct rejection contrast, and they were outside regions associated with retrieval of neutral episodic information. Several effects were valence-independent, including effects in the left amygdala. Other studies of both encoding and retrieval have reported activations in similar regions. Dolan et al. (2000) reported enhanced left amygdala activity during recognition of emotional vs. neutral pictures, while Maratos et al. (2001) reported a nearby region in a comparison of neutral words encoded in negatively vs. neutrally valenced sentences (and a trend in the same region for the positive vs. neutral contrast). In addition, Buchel et al. (1999) reported effects in left amygdala in response to a negatively conditioned stimulus (in the absence of an unconditioned stimulus), while Phelps et al. (2001) observed an enhanced response in this same region to a stimulus which subjects had been informed was associated with the threat of mild electric shock (no shock was actually experienced). Together, these data suggest that the amygdala is engaged by a variety of emotional memory processes, possibly 'tagging' retrieved memories with representations of their behavioural significance (Weiskrantz, 1956).

Valence-independent emotion effects were also evident in insular cortex, a finding also reported by Maratos et al. (2001). The insula is most commonly associated with processing of disgust (e.g., Calder et al., 2000; Phillips et al., 1997), but has also been reported in studies of fear conditioning (e.g., Critchley et al., 2002), instructed fear learning (Phelps et al., 2001), and viewing of both positive and negative pictures (Kuniecki et al., 2003). This structure may be preferentially engaged when emotional tasks are cognitively demanding or require internal generation of emotions (see Phan et al., 2002), possibly due to a role in representing emotional states (Damasio et al., 2000). Additional valence-independent emotion effects were found in medial orbitofrontal cortex and medial frontal gyrus. Activity in orbitofrontal cortex (OFC) and ventromedial prefrontal regions has been shown to correlate with individual subject ratings of emotional arousal (Phan et al., 2003) and has been proposed to reflect integration of emotional information derived from an extended emotional circuit (see Krawczyk, 2002). Another brain region showing greater activity for emotional than neutral stimuli was the right anterior cingulate cortex, a region reported to be involved in several different processes, including autonomic control (Critchley et al., 2000a,b), conflict monitoring (van Veen et al., 2001), emotion induction (Teasdale et al., 1999), memory retrieval (Cabeza and Nyberg, 2000) and problem solving (Prabhakaran et al., 1997). Activity in this area may index physiological arousal, whether this is induced by emotional or higher cognitive processing.

\section{Valence-specific emotion effects}

An extended area of left fusiform gyrus showed enhanced activity associated with negative hits. An overlapping region (though bilateral and more extensive) was reported by Lane et al.
(1999) during passive viewing of emotional pictures. This effect may result from re-entrant processing enhancing visual processing of emotional stimuli, even when, as in this case, this emotionality is only a product of a stimulus' study history (see Dolan, 2002). Positive and negative conditions both showed enhanced activity in anterior temporal lobe, previously suggested by Dolan et al. (2000) to reflect a state of emotional memory retrieval.

\section{Common emotion effects at encoding and retrieval}

Some brain regions showed significant emotion effects during both encoding and retrieval. As noted earlier, the left angular gyrus is involved in semantic processing (see Price, 2000), suggesting that semantic assessment of stimuli is enhanced when those stimuli are tagged as being behaviourally significant in some way, due either to current or previous association with emotional stimuli. Overlapping regions of left amygdala also showed enhanced activity during both encoding and retrieval of items associated with emotional backgrounds. Similar areas have been reported in other encoding tasks, and related to subsequent memory performance (Erk et al., 2003; Hamann et al., 1999). It may be that the amygdala is important for representing emotional information whether this comes from external or internal sources (see also Phelps et al., 2001; Pitkanen et al., 1997).

It should be noted that contrasts included only subsequently remembered items, so as to obviate effects arising from differences in subsequent memory across conditions. This does, however, restrict the present findings to successful encoding and retrieval, and processing of subsequently forgotten items might be rather different.

\section{Caveats}

The above discussion is predicated on the assumption that contrasts between conditions arise solely as a result of the emotional differences between backgrounds. However, other possibilities exist - in general, emotional backgrounds were more arousing, more interesting and more novel than their neutral counterparts. Furthermore, formation of associations between backgrounds and paired objects possibly may have been easier when there was an obvious or natural connection, which may have been more common in the neutral encoding condition. In a previous control study where neutral items were divided by how novel and interesting they were, we failed to observe differences in the ERPs elicited by recognised items that had been encoded with high vs. low novelty neutral backgrounds, but still observed differences between those encoded with emotional vs. neutral backgrounds (unpublished data). It is still possible that nonemotional differences between contexts contribute to the effects reported here, but any such effects are likely to be small in magnitude compared to the emotion-specific effects.

A further caveat relates to the valence-specific effects, as these may arise from differences in recognition performance or confidence (in the case of positive $>$ negative effects) or as effects of arousal (as negative stimuli were, on average, more arousing than their positive counterparts) as well as differences between the processing of negative and positive emotions. While high-threshold arousal effects could have contributed to emotion-specific effects, it should be noted that they do not overlap with the valence-independent emotion effects, which 
partly reflect arousal differences between emotional and neutral stimuli. Though contrasts were limited to correctly recognised items, differences in confidence between conditions cannot be ruled out as contributing to the effects reported here, and it may be of interest in the future to examine the effects of emotion on retrieval processing of items recognised with varying degrees of confidence.

\section{Conclusions}

In conclusion, brain activity associated with recognition of pictorial stimuli was shown to be modulated as a function of the emotional context associated with such stimuli during encoding, in accordance with previous ERP evidence (Smith et al., in press) and an fMRI study using a similar approach, but with verbal material (Maratos et al., 2001). The effects reported in this study are qualitatively similar to those elicited by neutral words studied in emotional sentences (Maratos et al., 2001). While some differences between the reported activations can be observed, the principal effects of emotion in engaging an extended emotional circuit, as well as modifying retrieval and post-retrieval processing, appear to be common across verbal and nonverbal modalities.

The various changes in processing reported here were elicited in a task where the emotional manipulation has no relevance to the retrieval task, and one interesting question relates to whether some effects arise from automatic and obligatory engagement of processes that could be engaged for neutral memories where contextual information is task-relevant. Previous ERP work has suggested that changes may arise from both changes in the value of the stimulus itself, and its role as a cue for retrieval of contextual information, reflecting two distinct interactions between emotion and memory which can drive more effective processing of and reaction to stimuli which have emotional significance.

\section{Acknowledgment}

This research was supported by the Wellcome Trust. RNAH and MDR are supported by the Wellcome Trust.

\section{References}

Ashby, F.G., Isen, A.M., Turken, A.U., 1999. A neuropsychological theory of positive affect and its influence on cognition. Psychol. Rev. 106 (3), $529-550$

Bechara, A., Damasio, H., Damasio, A.R., 2000. Emotion, decision making and the orbitofrontal cortex. Cereb. Cortex 10 (3), 295-307.

Buchel, C., Dolan, R.J., Armony, J.L., Friston, K.J., 1999. Amygdala-hippocampal Involvement in Human Aversive Trace Conditioning revealed through event-related fMRI. J. Neurosci. 19 (24), 10869-10876.

Cabeza, R., Nyberg, L., 2000. Neural bases of learning and memory: functional neuroimaging evidence. Curr. Opin. Neurol. 13 (4), 415-421.

Cahill, L., 1999. A neurobiological perspective on emotionally influenced, long-term memory. Semin. Clin. Neuropsychiatry 4 (4), 266-273.

Calder, A.J., Keane, J., Manes, F., Antoun, N., Young, A.W., 2000. Impaired recognition and experience of disgust following brain injury. Nat. Neurosci. 3 (11), 1077-1078.

Cansino, S., Maquet, P., Dolan, R.J., Rugg, M.D., 2002. Brain activity underlying encoding and retrieval of source memory. Cereb. Cortex 12 (10), $1048-1056$.
Critchley, H.D., Elliot, R., Mathias, C.J., Dolan, R.J., 2000a. Neural activity relating to generation and representation of galvanic skin conductance responses: a fMRI study. J. Neurosci. 20 (8), 3033-3040.

Critchley, H.D., Corfield, D.R., Chandler, M.P., Mathias, C.J., Dolan, R.J., 2000b. Cerebral correlates of autonomic cardiovascular arousal: a functional neuroimaging investigation in humans. J. Physiol. 523 (1), $259-270$.

Critchley, H.D., Melmed, R.N., Featherstone, E., Mathias, C.J., Dolan, R.J., 2002. Volitional control of autonomic arousal: a fMRI study. NeuroImage 16 (4), 909-919.

Damasio, A.R., Grabowski, T.J., Bechara, A., Damasio, H., Ponto, L.L., Parvizi, J., Hichwa, R.D., 2000. Subcortical and cortical brain activity during the feeling of self-generated emotions. Nat. Neurosci. 3 (10), $1049-1056$.

Dolan, R.J., 2002. Emotion, cognition and behaviour. Science 298 (5596), $1191-1194$.

Dolan, R.J., Lane, R., Chua, P., Fletcher, P., 2000. Dissociable temporal lobe activations during emotional episodic memory retrieval. NeuroImage 11, 203-209.

Eldridge, L.L., Knowlton, B.J., Furmanski, C.S., Bookheimer, S.Y., Engel, S.A., 2000. Remembering episodes: a selective role for the hippocampus during retrieval. Nat. Neurosci. 3 (11), 1149-1152.

Erk, S., Kiefer, M., Grothe, J., Wunderlich, A.P., Spitzer, M., Walter, H., 2003. Emotional context modulates subsequent memory effect. NeuroImage 18 (2), 439-447.

Friston, K.J., Frith, C.D., Frackowiak, R.S., Turner, R., 1995. Characterizing dynamic brain responses with fMRI: a multivariate approach. NeuroImage 2 (2), 166-172.

Friston, K.J., Fletcher, P., Josephs, O., Holmes, A., Rugg, M.D., Turner, R., 1998. Event-related fMRI: characterising differential responses. NeuroImage 7 (1), 30-40.

Friston, K.J., Penny, W., Phillips, C., Kiebel, S., Hinton, G., Ashburner, J., 2002. Classical and Bayesian inference in neuroimaging: theory. NeuroImage 16 (2), 465-483.

Hamann, S.B., 2001. Cognitive and neural mechanisms of emotional memory. TICS 5 (9), 394-400.

Hamann, S.B., Ely, T.D., Grafton, S.T., Kilts, C.D., 1999. Amygdala activity related to enhanced memory for pleasant and aversive stimuli. Nat. Neurosci. 2, 289-293.

Henson, R.N., Rugg, M.D., Shallice, T., Josephs, O., Dolan, R.J., 1999a. Recollection and familiarity in recognition memory: an event-related functional magnetic resonance imaging study. J. Neurosci. 19 (10), $3962-3972$.

Henson, R.N., Shallice, T., Dolan, R.J., 1999b. Right prefrontal cortex and episodic memory retrieval: a functional MRI test of the monitoring hypothesis. Brain 122 (7), 1367-1381.

Henson, R.N., Rugg, M.D., Shallice, T., Dolan, R.J., 2000. Confidence in recognition memory for words: dissociating right prefrontal roles in episodic retrieval. J. Cogn. Neurosci. 12 (6), 913-923.

Henson, R.N., Cansino, S., Herron, J.E., Robb, W.G., Rugg, M.D., 2003. A familiarity signal in human anterior medial temporal cortex? Hippocampus $13(2), 301-304$.

Konishi, S., Wheeler, M.E., Donaldson, D.I., Buckner, R.L., 2000. Neural correlates of episodic retrieval success. NeuroImage 12 (3), 276-286.

Krawczyk, D.C., 2002. Contributions of the prefrontal cortex to the neural basis of human decision making. Neurosci. Biobehav. Rev. 26 (6), $631-664$.

Kuniecki, M., Urbanik, A., Sobiecka, B., Kozub, J., Binder, M., 2003. Central control of heart rate changes during visual affective processing as revealed by fMRI. Acta Neurobiol. Exp. (Warsaw) 63 (1), $39-48$.

Lane, R.D., Chua, P.M., Dolan, R.J., 1999. Common effects of emotional valence, arousal and attention on neural activation during visual processing of pictures. Neuropsychologia 37 (9), 989-997.

Lang, P.J., Bradley, M.M., Cuthbert, B.N., 1997. The International Affective Picture System (IAPS): Photographic Slides. University of Florida, Gainesville, FL. 
Maratos, E.J., Rugg, M.D., 2001. Electrophysiological correlates of the retrieval of emotional and non-emotional context. J. Cogn. Neurosci. $13,877-891$

Maratos, E.J., Dolan, R.J., Morris, J.S., Henson, R.N., Rugg, M.D., 2001. Neural activity associated with episodic memory for emotional context. Neuropsychologia 39, 910-920.

McGaugh, J.L, Cahill, L., Roozendaal, B., 1996. Involvement of the amygdala in memory storage: interaction with other brain systems. Proc. Natl. Acad. Sci. U. S. A.

Otten, L.J., Henson, R.N.A., Rugg, M.D., 2002. State-related and itemrelated neural correlates of successful memory encoding. Nat. Neurosci. 5 (12), 1339-1344.

Phan, K.L., Wager, T., Taylor, S.F., Liberzon, I., 2002. Functional neuroanatomy of emotion: a meta-analysis of emotion activation studies in PET and fMRI. NeuroImage 16 (2), 331-348.

Phan, K.L., Taylor, S.F., Welsh, R.C., Decker, L.R., Noll, D.C., Nichols, T.E., Britton, J.C., Liberzon, I., 2003. Activation of the medial prefrontal cortex and extended amygdala by individual ratings of emotional arousal: a fMRI study. Biol. Psychiatry 53 (3), 211-215.

Phelps, E.A., O’Connor, K.J., Gatenby, J.C., Gore, J.C., Grillon, C., Davis, M., 2001. Activation of the left amygdala to a cognitive representation of fear. Nat. Neurosci. 4 (4), 437-441.

Phillips, M.L., Young, A.W., Senior, C., Brammer, M., Andrew, C., Calder, A.J., Bullmore, E.T., Perrett, D.I., Rowland, D., Williams, S.C., Gray, J.A., David, A.S., 1997. A specific neural substrate for perceiving facial expressions of disgust. Nature 389 (6650), $495-498$

Pitkanen, A., Savander, V., LeDoux, J.E., 1997. Organization of intraamygdaloid circuitries in the rat: an emerging framework for understanding functions of the amygdala. Trends Neurosci. 20 (11), $517-523$.

Prabhakaran, V., Smith, J.A., Desmond, J.E., Glover, G.H., Gabrieli, J.D., 1997. Neural substrates of fluid reasoning: an fMRI study of neocortical activation during performance of the Raven's Progressive Matrices Test. Cogn. Psychol. 33 (1), 43-63.
Price, C.J., 2000. The anatomy of language: contributions from functional neuroimaging. J. Anat. 197 (3), 335-359.

Rombouts, S.A., Barkhof, F., Witter, M.P., Machielsen, W.C., Scheltens, P., 2001. Anterior medial temporal lobe activation during attempted retrieval of encoded visuospatial scenes: and event-related fMRI study. NeuroImage 14 (1), 67-76.

Rugg, M.D., Allan, K., 2000. Memory retrieval: an electrophysiological perspective. In: Gazzaniga, M.S. (Ed.), The New Cognitive Neurosciences, 2nd ed. MIT Press, Cambridge, pp. 805-816.

Rugg, M.D., Otten, L.J., Henson, R.N.A., 2002. The neural basis of episodic memory: evidence from functional neuroimaging. Philos. Trans. R Soc. London, Ser. B 357 (1424), 1097-1110.

Smith, A.P.R., Dolan, R.J., Rugg, M.D., in press. Event-related potential correlates of the retrieval of emotional and non-emotional context. J. Cogn. Neurosci.

Stark, C.E., Okado, Y., 2003. Making memories without trying: medial temporal lobe activity associated with incidental memory formation during recognition. J. Neurosci. 23 (17), 6748-6753.

Strange, B.A., Hurlemann, R., Dolan, R.J., 2003. An emotion-induced retrograde amnesia in humans is amygdala- and beta-adrenergic-dependent. Proc. Natl. Acad. Sci. U. S. A. 100 (23), 13626-13631.

Taylor, S.F., Liberzon, I., Fig, L.M., Decker, L.R., Minoshima, S., Koeppe, R.A., 1998. The effect of emotional content on visual recognition memory: a PET activation study. NeuroImage 8 (2), 188-197.

Teasdale, J.D., Howard, R.J., Cox, S.G., Ha, Y., Brammer, M.J., Williams, S.C., Checkley, S.A., 1999. Functional MRI study of the cognitive generation of affect. Am. J. Psychiatry 156 (2), 209-215.

van Veen, V., Cohen, J.D., Botvinick, M.M., Stenger, V.A., Carter, C.S., 2001. Anterior cingulate cortex, conflict monitoring and levels of processing. NeuroImage 14 (6), 1302-1308.

Weiskrantz, L., 1956. Behavioural changes associated with ablation of the amygdaloid complex in monkeys. J. Comp. Physiol. Psychol. 49, $381-391$.

Zald, D.H., 2003. The human amygdala and the emotional evaluation of sensory stimuli. Brain Res. Rev. 41 (1), 88-123. 